\title{
Juan Pablo II y los obispos polacos hablan sobre Iglesia y política a propósito de la primera visita papal a Polonia en junio de 1979
}

\author{
John Paul II and the Polish bishops on the Church \\ and the politics on the occasion of the Pope's \\ first visit to Poland in June 1979
}

\section{Pablo PÉREZ LÓPEZ}

Departamento de Historia, Historia del Arte y Geografía

Universidad de Navarra

paperezlo@unav.es

https://orcid.org/0000-0002-2224-7472

\author{
Anna K. DULSKA \\ Instituto Cultura y Sociedad \\ Universidad de Navarra \\ adulska@unav.es \\ https://orcid.org/0000-0002-3350-5211
}

Resumen: Presentamos la versión española de un documento editado hasta ahora solamente en polaco. Recoge la transcripción de una conversación mantenida por el Consejo General de la Conferencia Episcopal de Polonia y el papa Juan Pablo II el 5 de junio de 1979 en Czestochowa, en el curso del primer viaje de Juan Pablo II a Polonia, que se desarrolló en junio de ese año. Era su segundo viaje pastoral, después del que había realizado a México. Se trata de una fuente de gran riqueza. Recoge con una franqueza nada común las opiniones del papa y de los obispos polacos sobre el significado y el alcance del viaje papal. Trata esencialmente de cuestiones pastorales y eclesiásticas, pero no elude los temas políticos, abordados de forma directa, clara y muy significativa desde el punto de vista histórico. El texto nos ofrece de primera mano un retrato crudo y sencillo de cómo vivía la Iglesia católica la opresión comunista y qué esperaban de un viaje como el que realizaba Juan Pablo II, de cuya trascendencia eran plenamente conscientes los participantes en aquel diálogo. Al hilo de la conversación se tiene noticia de la idea que poseen los interlocutores de qué significa la acción de la Iglesia católica y su gobierno, de cuál es el papel que puede corresponder a la Iglesia en Polonia en el seno de la Iglesia Universal, de cuáles eran algunas de las prioridades de gobierno de Juan Pablo II y de qué se esperaba de las autoridades comunistas y de otras autoridades religiosas en aquel momento y en el futuro.

Palabras clave: Juan Pablo I; Polonia; Iglesia católica; comunismo; Unión Soviética. 


\section{INTRODUCCIÓN}

Ponemos aquí a disposición de los hispanohablantes un texto recientemente publicado en polaco que tiene una riqueza e importancia singulares: la transcripción de una conversación mantenida por el Consejo General de la Conferencia Episcopal de Polonia ${ }^{1}$ y el papa Juan Pablo II el 5 de junio de 1979 en Częstochowa, en el curso del primer viaje de Juan Pablo II a Polonia, que se desarrolló entre los días 2 y 10 de junio de ese año. Fue su segundo viaje pastoral, después del realizado a México, con un breve paso por la República Dominicana y las Bahamas, entre el 25 de enero y el 1 de febrero del mismo año.

La fuente tiene varias peculiaridades que la hacen única. En primer lugar, el contexto en que se origina: una conversación de extremada confianza entre Karol Wojtyła, convertido en el papa Juan Pablo II, con sus compañeros de la jerarquía polaca. Se advierte en el tono y el contenido la ausencia de prevenciones nacidas de la necesidad de moderar el discurso, como es habitual ante otras

1 La Conferencia Episcopal de Polonia es el órgano colegiado de los obispos de Polonia; fue creado en 1918, año en el que Polonia volvió a ser independiente en el mapa de Europa. La primera asamblea plenaria tuvo lugar en 1919 en Gniezno. La Conferencia continuó su funcionamiento a lo largo de la ocupación alemana del país durante la Segunda Guerra Mundial y durante la posterior ocupación soviética. Regula su estructura y composición el estatuto que le otorga personalidad jurídica según el derecho canónico. El primero, aprobado en 1969, fue fruto de las deliberaciones del Concilio Vaticano II sobre la importancia de colegialidad en la Iglesia. Los consecutivos estatutos fueron promulgados en 1987, 1996 y, más recientemente, en 2009. Según el ordenamiento vigente en 1979, componían la estructura de la Conferencia los siguientes órganos: asamblea plenaria, consejo de obispos diocesanos, presidente (cargo reservado para el primado hasta 1996, cuando fue convertido en electivo) y vicepresidente (entre 1969 y 1978 cargo ocupado por Karol Wojtyła), mesa, consejo general (luego renombrado como consejo permanente), secretario general y comisiones permanentes del episcopado. El consejo general había sido creado ya en octubre 1945 como órgano decisivo en los asuntos más importantes de la Iglesia polaca, entre ellos, dirigir con autonomía sus relaciones con las autoridades comunistas. Estuvo compuesto por los obispos más prominentes, sobre todo los metropolitanos, y presidido por el primado. Sus directrices eran vinculantes para todo el episcopado y el clero en general. El consejo se reunía de forma regular en vísperas de las asambleas plenarias o en sesiones extraordinarias. Véase: Michał BIAŁKOWSKI, Udziat Karola Wojtyly w pracach Konferencji Episkopatu Polski i jej komisji specjalistycznych (1958-1978), en Studia Salvatoriana Polonica, 12 (2018), pp. 275-321; Jan DYDUCH, Ksztatt prawny Konferencji Episkopatu Polski, en Prawo Kanoniczne, 55/2 (2012), pp. 3-15; Rafał ŁATKA, Rada Gtówna Episkopatu Polski a pierwsza pielgrzymka fana Pawta II do Ojczyzny w 1979 r., en Dzieje Najnowsze, 1 (2018), pp. 229-262; Rafał ŁATKA, Rada Gtówna Episkopatu Polski a stan wojenny, en Glaukopis 34 (2017), pp. 159-186; Marek STĘPIEŃ, Status prawny i organizacja Konferencji Episkopatu Polski, en Artur MizińSKI (dir.), 100-lecie Konferencji Episkopatu Polski. Księga Jubileuszowa, Kielce, 2019, pp. 52-91; Stanisław WILK, Poczatki Konferencji Episkopatu Polski, en Artur MIZIŃSKI (dir.), 100-lecie Konferencji Episkopatu Polski. Księga fubileuszowa, Kielce, 2019, pp. 15-50. 
audiencias, que es lo que teníamos a disposición hasta hace muy poco. En esta sesión en Jasna Góra la confianza fue completa, y nos permite ver con claridad cuáles eran los objetivos del pontífice en su país y cómo se articulaban con los que tenía para la Iglesia en general en los comienzos de su pontificado. A esto se añade otro factor determinante: la situación política de Polonia -el placet de las autoridades al viaje no se había concretado hasta fechas recientes- hacía que la cuestión de la relación con las autoridades resultara crucial y se convirtiera en asunto central de la conversación. Así fue, y eso nos permite conocer las ideas en cuanto a la relación con los poderes políticos de un papa llamado a tener un importante peso en Europa y en el mundo en este aspecto. Finalmente, la confianza con la que hablaron permitió que abordasen temas que raras veces trata en público un miembro de la jerarquía católica: qué piensan del gobierno de la Iglesia, y de las relaciones entre la Santa Sede y los episcopados nacionales.

El texto ha sido publicado en polaco en 2019 por Andrzej Grajewski². De esa versión hemos partido para preparar una versión española. No presentamos una traducción del texto íntegro, sino solo los fragmentos que son de mayor interés para un público general, dejando de lado los más específicamente referidos a asuntos internos polacos, que resultarían oscuros si no se acompañan de una prolija explicación del contexto que los hiciera comprensibles ${ }^{3}$.

Así pues, el interés de los asuntos tratados y la libertad con que se expresan los intervinientes son los dos elementos que hacen especialmente valioso el contenido de esas páginas. De alguna forma lo resumió el propio Juan Pablo II en su intervención cuando expresó en voz alta las características del modo de trabajar de ese Consejo General y por qué le resultaba grato: «El Santo Padre también expresó su alegría por la reunión con el Consejo General. -Echo de menos al estilo del trabajo del Consejo General- dijo. Siempre me alegra mucho y me atrae

2 Andrzej GRAJEWSKI (ed.), Sprawy, które tocza się w Polsce, maja znaczenie światowe. Niepublikowane przemówienie Jana Pawta II do Rady Gtównej Episkopatu Polski, Jasna Góra, 5 czerwca 1979 r., introducción de Jan Kopiec, epílogo de Paweł Skibiński, Warszawa, 2019. El documento original se conserva en el Archivo de la Arquidiócesis de Varsovia: Archiwum Archidiecezji Warszawskiej, Sekretariat Prymasa Polski, 04/34.

3 Más específicamente, se han excluido de la traducción fragmentos sobre la evaluación de la situación doméstica, el tema de la normalización de las relaciones entre la Iglesia polaca y el régimen comunista, opiniones sobre las reacciones de los dignatarios del régimen comunista ante el viaje papal, las reflexiones personales del cardenal Wyszyński o las cuestiones personales. Todos estos elementos son de sumo interés para quien investiga las relaciones Iglesia-Estado en el bloque soviético, pero requerirían una profunda introducción y amplios comentarios que sobrecargarían el texto para un lector no familiarizado o no interesado. 
un intercambio libre del pensamiento. Os estaría muy agradecido -continuó- si quisierais decirle al papa qué es lo que pensáis y sentís».

El interés histórico de un documento de estas características apenas si requiere explicitación: nos ofrece las claves del pensamiento del papa y del episcopado polaco antes de que se produjeran hechos de gran trascendencia política para Polonia y para el mundo y, justamente, se habla de ellos antes de que nada de eso pudiera ser concebido como un futuro previsible. Por otro lado, las cuestiones tratadas no eran solo asunto polaco, aunque trataran especialmente de Polonia. Como destaca el papa, Polonia, con su llegada a la sede de Pedro, tiene ahora una dimensión mundial. Ese elemento simbólico constituye una realidad histórica de envergadura. Tampoco fueron solo asunto eclesiástico, aunque los interlocutores hablaran especialmente de la Iglesia: la acción pastoral que pretendían no podía sino tener efectos de calado en la vida social y política. Por último, no trataron de asuntos temporales, sino que analizaron los acontecimientos desde el punto de vista de la fe religiosa, aunque sin dejar de lado sus efectos mundanos.

Acompañamos la versión castellana de los fragmentos seleccionados de ese texto de dos elementos que pretenden facilitar su comprensión: una breve aproximación al contexto histórico en que tuvo lugar esa conversación, y un sucinto estudio crítico de los contenidos del debate.

Esta tarea no hubiera sido posible sin el generoso apoyo del profesor Paweł Skibiński, del Centro de Pensamiento de Juan Pablo II (Centrum Myśli Jana Pawła II) de Varsovia. La traducción del original polaco ha sido realizada por Anna K. Dulska, con pequeños ajustes en castellano de Pablo Pérez López. Hemos procurado ser fieles a la literalidad del texto y evitar versiones libres para que se transparente en la medida de lo posible el estilo de los intervinientes, claramente perceptible en polaco. Conviene recordar que se trata de la transcripción de la grabación de una conversación, no de un texto escrito, lo que añade falta de claridad expositiva a las afirmaciones o las preguntas, que estuvieron acompañadas de un lenguaje corporal ahora ausente. Con todo, hemos preferido recurrir a la anotación antes que tomarnos libertades frente a la literalidad en a la creación de la versión española.

\section{CONTEXTO HISTÓRICO DE UNA CONVERSACIÓN}

La elección de Juan Pablo II tuvo lugar a finales de la década de los setenta. En la Iglesia católica la situación era difícil. La enorme esperanza de renovación suscitada inicialmente por la celebración del Concilio Vaticano II había dado paso 
a una crisis interna que parecía hacer ingobernable la Iglesia y puso en cuestión desde sus fundamentos hasta sus modos de hacer. Una crisis acompañada de una ola de deserciones de clérigos y religiosos en los países occidentales que parecía poner en riesgo de disolución a la institución. $\mathrm{Al}$ menos en algunos lugares, todo era incertidumbre ${ }^{4}$.

En el ámbito político, fueron los años en que el poder mundial de la Unión Soviética alcanzó su punto más alto. El prestigio de la alternativa comunista parecía crecer en paralelo con el desprestigio del bloque de las democracias lideradas por EE.UU. El caso Watergate, la dimisión de Nixon, el fracaso de Vietnam, la crisis económica derivada de la guerra del Yom Kippur en 1973 que golpeaba a la economías norteamericana y a la de Europa Occidental eran argumentos que incidían en el mismo sentido. Todavía más, en el ámbito cultural, triunfaba una suerte de consenso filosocialista, que solo era desoído por algunas vanguardias intelectuales que estaban de vuelta del marxismo y del anarco individualismo, precisamente porque conocían bien lo que había sido mayo del 68 y lo que constituía su herencia. Pero eso eran entonces solo indicios de un posible cambio. Los hechos parecían ir por otro lado 5 .

Los soviéticos, además, podían jugar sus cartas en Europa con cierta ventaja gracias a los nuevos aires que habían soplado en las cancillerías europeas. En efecto, los años de Willy Brandt como canciller de la RFA (1969-1974) ofrecieron una oportunidad nueva. El canciller, antiguo alcalde de Berlín Oeste, tenía un plan para remodelar sus relaciones con la Alemania del Este y el Berlín del otro lado del muro. Estaba convencido de que la solución se podía encontrar a través de un Wandel durch Annäherung, un cambio mediante el acercamiento, en el que la RFA debía tomar la iniciativa al margen de los norteamericanos. Era su Ostpolitik, como se la conoció en la prensa internacional. No es coincidencia que el presidente Richard Nixon utilizara también por entonces el concepto de acercamiento: era efecto del cansancio que generaba la prolongada tensión de

4 George WeIgel, Biografía de Juan Pablo II. Testigo de esperanza, Barcelona, 1999, pp. 326-332; José ANDRÉS-GallegO, Antón PAZOS, La Iglesia en la España contemporánea (1936-1998), Madrid, 1999, pp. 157-174. Una clarificadora interpretación de la recepción del Concilio en BENEDICTO XVI, Discurso a los cardenales, arzobispos, obispos, y prelados superiores de la curia romana, 22/12/2005, http://www.vatican.va/content/benedictxvi/es/speeches/2005/december/documents/hf_ben_xvi_spe_20051222_roman-curia.html [consultado: 22/12/2020].

5 François FURET, El pasado de una ilusión. Ensayo sobre la idea comunista en el siglo XX, México, 1995, pp. 11-13 y 557-570; Georges-Henri SouTOU, La Guerre de Cinquante ans. Les relations Est-Ouest 1943-1990, Paris, 2001, pp. 567-568. 
la Guerra Fría en los gobernantes occidentales ${ }^{6}$. El razonamiento de los socialdemócratas en el poder era que la RFA debía considerarse una Alemania liberada del nazismo más que conquistada y ocupada, y que cabía pensar algo análogo de la parte configurada como la RDA. Si se admitía eso, el horizonte sería el reconocimiento mutuo, acompañado del reconocimiento de la línea Oder-Neisse como frontera oriental, y de caminar hacia la normalización de relaciones. $\mathrm{Pa}$ rece que trataba de no alejarse de una futura unificación, sino de caminar hacia ella eliminando el obstáculo que suponía el enfrentamiento sostenido y cerrado entre las dos Alemanias.

La propuesta de Brandt era tanto como ensayar un nuevo orden europeo, en buena medida próximo al que habían propuesto los soviéticos después de Stalin: finlandizar Alemania y convertirla en dominio conjunto de los propios alemanes y la URSS. Ciertamente, ni siquiera en su propio partido, el SPD, había unidad al respecto. El ministro de Defensa de Brandt, Helmut Schmidt, por ejemplo, era partidario de soluciones más atlantistas y estaba en contra de trabajar en un nuevo orden de seguridad europeo en colaboración con los soviéticos. Es posible que este debate estuviera en la raíz de la caída de Brandt en 19747.

La Ostpolitik de la RFA cosechó un éxito temprano en 1970 con la firma de un tratado que se negoció en secreto: el tratado de Moscú, firmado el 12 de agosto de ese año. Perseguía facilitar una solución política nueva para el conjunto del problema alemán a cambio de la cooperación económica de la RFA con la URSS y la RDA. La negociación se centró en diez puntos que se sustanciaron en cuatro asuntos recogidos en el tratado: primero, la voluntad de distensión y normalización de Europa en el statu quo del momento de la firma. El término «normalización» es interesante para entender algunos elementos del debate episcopal que nos ocupará. Segundo, la renuncia a amenazas o violencia. Tercero, el reconocimiento de las fronteras europeas como inviolables, aunque no inalterables, lo que dejaba abierta la puerta, por ejemplo, a una reunificación pactada. Y cuarto, la intención de no revisar acuerdos anteriores, como los de

6 «After a period of confrontation, we are entering an era of negotiation». First Inaugural Address of Richard Mulhouse Nixon, https://avalon.law.yale.edu/20th_century/nixon1.asp [consultado: 13/01/2020]; Heinrich August WINKLER, Der lange Weg nach Westen II. Deutsche Geschichte vom «Dritten Reich» bis zur Wiedervereinigung, München, 2000, pp. 279-290; Willy BRANDT, Memorias, Madrid, 1990, pp. 214-246.

7 Georges-Henri SoUTOU, La Guerre... [ver n. 5], p. 501. El escándalo conocido como affaire Guillaume sacó a la luz pública que uno de los más cercanos colaboradores de Willy Brandt, Günter Guillaume, y su mujer, eran espías de la RDA. Brandt dimitió a causa de esto el 7 de mayo de 1974. Willy BRANDT, Memorias, pp. 346-375. 
Potsdam o el Tratado del Atlántico Norte. Además, el acuerdo hacía referencia a las relaciones con otros países de la órbita soviética, como la RDA, Polonia o Checoslovaquia, y al horizonte de la entrada en la ONU de las dos Alemanias. Se acordaba también impulsar las relaciones económicas y tecnológicas, y se auguraba, finalmente, la celebración de una conferencia sobre seguridad en Europa. Es decir, en buena medida se recogían viejas aspiraciones soviéticas sin que constara un reconocimiento escrito de la voluntad de reunificación alemana: los soviéticos garantizaban la libertad de acceso a Berlín Oeste desde la RFA, una vieja reivindicación occidental. La aprobación del tratado, intensamente debatido, fue el símbolo de la nueva política. Suponía, desde luego, una novedad importante respecto a los años anteriores ${ }^{8}$.

$\mathrm{Al}$ tratado con la URSS siguió la firma de otro entre la RFA y Polonia que, sin que nadie lo adivinara, influyó indirectamente en el futuro del socialismo y de los dos países. El gobierno comunista polaco pensó que la buena imagen asociada al éxito que suponía la nueva actitud de la RFA, le brindaba la oportunidad que estaba buscando para solucionar sus problemas económicos. Decidió aprobar una fuerte subida de precios que resultó lógicamente impopular entre los trabajadores, cuyos sueldos eran ya bajos. La protesta terminó en levantamiento y en una represión que se cobró más de cuarenta muertos y miles de heridos. Władysław Gomułka fue sustituido al frente del Partido Obrero Unificado Polaco (POUP), como se llamaba la organización comunista en Polonia. Estos hechos provocaron, sin que se notara, la fermentación de un movimiento obrero al que se sumaron paulatinamente intelectuales descontentos que se distanciaban de las posturas oficiales del POUP?.

En definitiva, la Ostpolitik se configuró como un gran factor de cambio para las relaciones internacionales en el mundo y, especialmente, en Europa. En el ambiente general del viejo continente fue notable el impulso que esta política dio a las tesis marxistizantes. Para esta corriente de opinión, la solución al conflicto que dividía al mundo estaría en un socialismo templado que conseguiría atraer a los soviéticos e implantar regímenes de justicia e igualdad alejados de las ideas liberales y del capitalismo. El final de la Guerra Fría estaría en la convergencia, y esta se identificaba con la socialdemocracia. Conviene recordar que, incluso en

8 Vladislav M. ZuboK, Un imperio fallido. La Unión Soviética durante la Guerra Fría, Barcelona, 2008, pp. 316-323. Heinrich August WINKLER, Der lange... [ver n. 6], pp. 279-290.

9 Wanda JARZĄBEK, Polska w polityce międzynarodowej $i$ «Zimnej wojnie», 1945-1989, en Krzysztof Persak, Paweł MachCeWICZ, Polski wiek XX, t. IV, Warszawa, 2010, pp. 315-320; Wojciech RoszKOWSKI, Historia Polski 1914-2015, Warszawa, 2017, pp. 340-344. 
ambientes eclesiásticos católicos, esta idea parecía monopolizar cualquier pensamiento benévolo sobre el futuro ${ }^{10}$.

La Conferencia sobre la Seguridad y Cooperación en Europa que se celebró en Helsinki (1973-1975) pareció confirmar todo esto. El Acta firmada como culminación de aquellas largas negociaciones supuso reconocer el statu quo europeo y la posición de dominio de la URSS sobre media Europa. Era la convalidación de su poder de hecho. Pero hubo un logro durante la conferencia, debido a la presión francesa y de la Santa Sede, que pareció pequeño y no lo fue. La llamada «tercera cesta» de la negociación culminó en una declaración sobre el respeto a los derechos humanos que tuvo una importancia inesperada en un plazo relativamente breve ${ }^{11}$. Los propios soviéticos se dieron cuenta y en el politburó hubo una tormentosa discusión al respecto. Una vez publicado en Pravda, aquel texto se convirtió en una referencia pública que los disidentes invocaban en nombre de lo establecido por sus propios dirigentes. Esa línea de fractura, inicialmente pequeña, se iría ampliando hasta hacer sentir a los dirigentes comunistas la fuerza de la opinión pública, que hasta entonces nunca habían tenido en consideración ${ }^{12}$.

Con todo, la CSCE era un éxito político a corto plazo de gran envergadura para la URSS. Unida a la Ostpolitik parecía confirmar el triunfo de su política en Europa y dotarla de estabilidad. Así las cosas, Moscú, beneficiada por el aumento del precio del petróleo que exportaba, se sintió en condiciones de continuar su política de presión expansiva en el mundo, especialmente exitosa en África y América Latina en estos años ${ }^{13}$.

Europa occidental, mientras tanto, trataba de asimilar los nuevos aires surgidos de la revuelta de 1968 y de capear el temporal de la crisis económica. El Reino Unido, una vez que de Gaulle dejó el poder en Francia, consiguió ingresar en las Comunidades Europeas al mismo tiempo que Irlanda y Dinamarca, en 1973. El entusiasmo por la causa europeísta permitió crear un sistema moneta-

10 Pablo PÉrez López, El mundo en que vio la luz el Concilio, en Antonio ARANDA, Miguel LLUCH, Jorge HerRera (eds.), En torno al Vaticano II: claves históricas, doctrinales y pastorales, Pamplona, 2014, pp. 47-68.

11 Emmanuel DeCaux, La Conférence sur la sécurité et la coopération en Europe (CSCE), Paris, 1992; Jacques ANDRÉANI, Le piège: Helsinki et la chute du communisme, Paris, 2005; Victor-Yves GHEBALI, La diplomatie de la détente, la CSCE, d'Helsinki á Vienne (1973-1989), Bruxelles, 1989, pp. 265362. Petri HaKKaRAINEN, A state of peace in Europe. West Germany and the CSCE, 1966-1975, New York, 2011, pp. 213-257.

12 Arkadi N. SHEvchenko, Ruptura con Moscú, Barcelona, 1985, pp. 341-344. El autor detalla los debates internos soviéticos y cómo esto afectó a la carrera de algunos de los que negociaron con más entusiasmo estos acuerdos, luego denostados por la cúpula soviética.

13 Georges-Henri Soutou, La Guerre de Cinquante ans... [ver n. 5], pp. 559-565. 
rio unificado que preconizaba la creación de una moneda común, y la elección por sufragio universal directo de los parlamentarios europeos por primera vez en 1979 ${ }^{14}$. La democratización de Portugal, Grecia y España parecía confirmar que había una vía europea democrática y con futuro. Tanto era así que los comunistas italianos, franceses y españoles inventaron el término «eurocomunismo» para definir su nueva postura política de convergencia con la democracia burguesa ${ }^{15}$. Desde luego, no todo era de color de rosa. En Italia, el mismo año en que sería elegido papa Karol Wojtyła, la organización comunista Brigadas Rojas asesinó al político democristiano Aldo Moro, amigo personal del papa Pablo VI. En España el terrorismo también marxista y separatista de ETA iba en aumento, y no cesó cuando se inició la Transición a la democracia. En el Reino Unido el terrorismo del IRA motivó el despliegue del ejército en Irlanda del Norte, en Alemania la Fracción del Ejército Rojo golpeaba también de vez en cuando. El pulso por un modelo alternativo continuaba ${ }^{16}$. Del otro lado del telón de acero el pulso existía también, pero el terrorismo seguía siendo monopolio del Estado. La elección de un obispo venido de allí como cabeza de la Iglesia católica no parecía rimar con el tiempo que se vivía ${ }^{17}$.

\section{INTERLOCUTORES Y CONTENIDOS MÁS RELEVANTES DE LA CONVERSACIÓN}

Tras la elección de Karol Wojtyła como papa, se suscitó pronto la cuestión de su posible visita a su país de origen. Era una obviedad por una parte, y algo impensable por otra: ¿podía visitar un papa un país más allá del telón de acero? La propuesta se abrió camino con dificultad, conducida hábilmente desde Roma y por el episcopado polaco, y se concretó finalmente para los primeros días del mes de junio de 1979. En el cuarto día de la visita, el 5 de junio, tuvo lugar la

14 Charles ZorgBiBe, Histoire de la construction européenne, Paris, 1993, pp. 227-252; Nathalie Champroux, L'instauration du Système monétaire européen, en Entre convictions et obligations: Les gouvernements Thatcher et Major face au Système monétaire européen 1979-1997, Paris, 2009, http:// books.openedition.org/psn/7815 [consultado: 22/12/2020].

15 Augusto DEL NOCE, Italia y el eurocomunismo: una estrategia para occidente, Madrid, 1977; François FONVIEILLE-ALQUIER, El Eurocomunismo, Barcelona, 1979.

16 Michael Burleigh, Sangre y rabia. Una historia cultural del terrorismo, Madrid, 2008, pp. 255374.

17 Cfr. Pablo PÉrez López, El pontificado de Juan Pablo II y su tiempo, en Scripta Theologica, 51 (2019), pp. 129-157. DOI 10.15581/006.51.1.129-157. 
peregrinación de Juan Pablo II al santuario de la Virgen Negra de Jasna Góra en Częstochowa. En el mismo día y lugar fue celebrada la $169^{\circ}$ asamblea plenaria de la Conferencia del Episcopado de Polonia. En un descanso de las deliberaciones se convocó una reunión del Consejo General con el nuevo Papa polaco, en la que participó un grupo muy reducido.

Los miembros del Consejo General que se reunieron con Juan Pablo II en Jasna Góra el 5 de junio fueron el primado de Polonia, Cardenal Stefan Wyszyński; el arzobispo Jerzy Stroba, metropolitano de Poznań; el arzobispo Franciszek Macharski, metropolitano de Cracovia; Bronisław Dąbrowski, obispo auxiliar de Varsovia y secretario general de la Conferencia Episcopal; el arzobispo Henryk Gulbinowicz, metropolitano de Wrocław, y los obispos Lech Kaczmarek de Gdańsk e Ignacy Tokarczuk de Przemyśl. No asistió ningún representante de la delegación vaticana. En la selección que hemos realizado aparecen intervenciones del Papa, del primado y de Stroba, Kaczmarek y Tokarczuk.

Los asuntos tratados pueden clasificarse en dos grandes líneas que se desdoblan a su vez en otras dos: el gobierno de la Iglesia universal y de la Iglesia en Polonia en su doble dimensión, puramente eclesiástica en primer término, y en relación con el mundo secular -con la sociedad en general, sus gobernantes y sus líderes culturales- en segundo. La perspectiva polaca era el factor compartido por los interlocutores hasta la elección de Karol Wojtyła como papa. Era él, por tanto, el que introducía ahora la visión universal en la conversación, pero es muy interesante advertir cómo enfoca desde su responsabilidad general los problemas particulares de Polonia y cómo los obispos polacos le preguntan por la percepción que él tiene de lo que ocurre fuera y por cómo se les percibe.

Ese entrelazamiento de lo polaco y lo universal aparece ya en el comienzo de la intervención papal, que evoca el espíritu de diálogo que vivió en su relación con los obispos en Polonia como una de las mayores riquezas del gobierno de la Iglesia:

El Santo Padre agradeció al primado la introducción al diálogo que quería tener con el Consejo General. Lo hace en el espíritu de colegialidad, que es la forma de estar en la Iglesia. El diálogo es una fórmula invencible. Lo que el Santo Padre experimentó en Polonia desde el principio de su visita confirmó esa tesis. Así quedó manifiesto en la Plaza de la Victoria en Varsovia.

Lo reitera poco después, aludiendo veladamente a algo que parece que le faltara en el Vaticano: «Echo de menos el estilo del trabajo del Consejo General -dijo. Siempre me alegra mucho y me atrae un intercambio libre del pensamien- 
to». Este sería, por tanto, uno de los modos de gobierno de la Iglesia en Polonia que Juan Pablo II trataría de trasplantar a Roma.

El segundo argumento de la introducción papal es una referencia que enmarca el tono del contenido: «Qué hermosamente se manifestó el anhelo de Cristo por la sociedad de la capital [Varsovia]». Se trata de una idea clave en todo el argumentario: la misión pastoral responde a un hondo anhelo humano de fe y está a su servicio, por eso el contexto, por difícil que sea, es secundario: «Ellos [los fieles que manifiestan ese anhelo] tienen derecho a hacerlo, aunque resulte incómodo para alguien, [aunque] pueda dar lugar a temores». Es decir, que por encima de cualquier peligro político está el deber de responder a los anhelos de Dios que habitan en el pueblo.

Acotado por esos dos principios, comienza un diálogo en el que el Romano Pontífice establece una premisa que flota también sobre toda la conversación: desde el Concilio Vaticano II Polonia y los avatares de la Iglesia en ella tenían una dimensión universal, y ahora, con un polaco en la sede de Pedro, todavía más. La conversación será, por eso, un intercambio de pareceres sobre lo que sucede en Polonia, pero con la mirada puesta en su trascendencia universal: «lo que el episcopado polaco piensa, especialmente el Consejo General, es muy importante. Este es un asunto general».

Como un corolario inmediato de esa premisa aparece la cuestión de la política vaticana hacia Europa oriental -central y oriental, en realidad-, dicho en otros términos, hacia la Europa dominada por la URSS. Se trataba de lo que la prensa solía denominar la Ostpolitik vaticana, asimilando la actitud de Roma en los últimos años del pontificado de Pablo VI a la que había aparecido en la RFA -a la que hicimos antes referencia-. Juan Pablo II señala dos puntos para entender su postura: primero, que «Todo Occidente está cargado de complejos [frente al comunismo]»; segundo, que, si esos complejos dominaban al personal del Vaticano antes, ahora se reconoce que su propia presencia en Roma debe significar el abandono de los complejos y la adopción de una nueva mirada. Está en marcha, por tanto, una nueva política vaticana hacia la Europa comunista.

La demostración de que esa política es posible y de que ya es real, es el hecho mismo del viaje que está realizando, cuya trascendencia se irá perfilando y destacando a lo largo de la conversación. De la importancia que el papa le atribuye habla claramente el empeño con el que ha preparado ese viaje. Lo subraya comparándolo con el de enero a México: este es un viaje más difícil, ha habido que salvar obstáculos más graves para que se pueda producir y la mano de Dios está detrás del hecho de que haya sido posible. Juan Pablo II, consciente de su responsabilidad, ha preparado personal y cuidadosamente los discursos que va a 
pronunciar. No hay improvisación sino un plan detallado y completo. E insiste: esto es importante para Polonia, pero no solo para ella, lo es para toda Europa y para todo el mundo.

Quizá más importante todavía es algo que el papa polaco detalla a continuación:

[Al preparar mis intervenciones en este viaje] no dejaba de preguntarme una cosa: que esta amplia opinión occidental sopesaría lo que el papa dijo en México y lo que ha dicho en Polonia. En México, hablé muy directamente sobre la injusticia que existe allí; también podría hablar aquí, pero me he detenido a mitad de camino. Fue suficiente con ponernos de acuerdo en nuestros propios asuntos, los de familia, en la Plaza de la Victoria, ante Santa Ana, en la Colina del Lech en Gniezno -en nuestros propios asuntos- ${ }^{18}$.

Es decir, hay una intención táctica de contener la denuncia de la injusticia socialista para encontrar un camino gradual que evite la violencia, la confrontación pura y dura, y haga posible llegar a un cambio. Juan Pablo II conoce la rigidez del sistema, sabe que no van a ceder y que están prontos a la represión, pero quiere advertirles también, esta vez ante una audiencia mundial, que no pueden seguir como hasta ahora. El argumento tiene una dimensión estratégica más penetrante cuando el pontífice alude a continuación al hecho de que «existe el mundo eslavo, que existe Chequia, que existe Ucrania, que existen los lituanos, que existe la Rusia cristiana desde hace mil años». Es la evidencia de que su llamada a un cambio no se restringe a Polonia: abarca a todo el mundo eslavo, a la cuna misma del poder soviético. Llegado a ese punto, parece reflexionar en voz alta sobre hasta dónde podrá llegar el proceso de llamada a una transformación

18 Alusión a los discursos más emblemáticos pronunciados por el papa durante su viaje hasta el momento: en la Plaza de la Victoria en Varsovia, delante de la iglesia de Santa Ana de Varsovia, dirigido a la comunidad de estudiantes universitarios, y en Gniezno, la primera capital de Polonia (s. X), donde el papa se dirigió a los cristianos del círculo de la etnia y la cultura eslava, «pulmón oriental» de Europa. Quizás las palabras que más resonancia han tenido en la sociedad polaca (para los que asistieron en persona, pero también para los que siguieron la visita por las censuradas radio y televisión polacas, o a través de la también selectiva Radio Europa Libre, véase Anna K. DUlsKa, Ryszard DUlski, Halo, halo! Niepodlegta w eterze. Radio i radiofonia w Polsce, 1918 1989, Kraków, 2021, pp. 173-176), fueron las siguientes: «Clamo yo, el hijo de la tierra polaca, y yo, Juan Pablo II, papa. Clamo desde toda la profundidad de este Milenio, clamo en la víspera de Pentecostés, clamo con todos vosotros: ¡Que venga Tu Espíritu! ¡Qué venga Tu Espíritu y renueve la faz de la tierra, de esta tierra!». Su significado era doble: en el sentido religioso el papa llamaba a una renovación espiritual, mientras que en el sentido político aludía a la necesidad de transformación del régimen totalitario comunista a un sistema democrático. Como tal, sus palabras serán el cimiento del movimiento «Solidaridad», que nacerá el año siguiente. 
que ha inaugurado este viaje a Polonia, una reflexión que vale la pena comparar con lo que en realidad sucedió en los años siguientes. Tiene especial importancia esa conciencia del eco que tendrá su acción para todo el ámbito eslavo que el papa manifiesta desde el primer momento.

La actitud del papa ante las autoridades comunistas fue de una contención cuidadosamente considerada, y también de una firmeza ajena a cualquier ingenuidad: «recuerden, señores, que el papa, cuando viene aquí, arriesga más que ustedes ante el mundo entero. Porque se arriesga a darles una coartada que no se merecen». Ese será el juego político que está en marcha: la Iglesia ofrece contención y limitación de la crítica, ofrece incluso un elogio a la valentía que ha demostrado el gobierno de Edward Gierek al permitir el viaje, a cambio de la apertura que supone ese permiso para que el papa visite su propia tierra. Y esto no se hace pensando solo en Polonia, sino en todo el mundo dominado por el comunismo, y conscientes de que el comunismo no se merecería ese respeto si se atuviera a sus obras.

Hay, además, una dolorosa realidad eclesiástica que late bajo el dominio comunista: la rendición de la jerarquía de las iglesias ortodoxas a la presión de los Estados comunistas, y su alianza con la represión política para la liquidación de los católicos, especialmente de los católicos en Ucrania, pero también en $\mathrm{Ru}$ manía y Rusia ${ }^{19}$. A partir de aquí el papa hace un excurso interesante cuando menciona lo difícil que es hablar de este tema sin perjudicar la tarea ecuménica de acercamiento a las iglesias ortodoxas, y lo que esto exigirá para modificar la línea de trabajo en el Vaticano.

Juan Pablo II terminó esta primera intervención suya destacando los dos puntos que consideraba nucleares en su viaje: primero, insistió, la trascendencia mundial de lo que sucede en Polonia; segundo, cómo convivir con gobiernos comunistas como el de Gierek y, al mismo tiempo, conseguir cambios. Los dos puntos son esenciales para el gobierno de la Iglesia, en Polonia y en todo el mundo, y los dos tuvieron destacadas consecuencias sociales y políticas, locales y globales.

La intervención del cardenal primado, Stefan Wyszyński, recoge gran parte de lo que había dicho el papa, especialmente sobre Polonia, y lo refuerza con datos acerca de la negociación con el gobierno que él había dirigido. Conocemos,

19 Jan Mikrut (ed.), La Chiesa cattolica e il comunismo: in Europa centro-orientale e in Unione Sovietica, Verona, 2016, pp. 489-536 y 699-714. Y bajo la dirección del mismo autor La Chiesa cattolica in Unione Sovietica: dalla Rivoluzione del 1917 alla Perestrojka, Verona, 2017, pp. 769-795. Miembros destacados de las iglesias ortodoxas se plegaron a la presión política para sobrevivir y colaboraron en la represión de los católicos. 
gracias a sus palabras, la abundante tarea de diálogo con las autoridades comunistas y lo bien que conocían los prelados polacos la realidad interna de la vida política comunista, hasta ser conscientes de qué cabía esperar de ella, y qué no: «Os preferimos a vosotros que a lo desconocido», llega a decir Wyszyński a Gierek con una frase que es una muestra de apoyo y también una amenaza velada sobre la posibilidad de hacerles caer. Los eclesiásticos polacos no dudan en denunciar la manipulación y la mentira sobre las que se asienta el gobierno del POUP, pero le dejan una salida abierta, una continuidad posible a cambio de alguna cesión, como la autorización del viaje papal. Lo hicieron siendo plenamente conscientes de lo que significaba esa cesión limitada: «La presencia del papa [en Polonia] es una especie de rotura del telón de acero», dice Wyszyński con frase lapidaria que adelanta diez años lo que sucederá.

El conjunto de las explicaciones del primado llama la atención porque es indicio de prudente habilidad, por la paciencia y la tenacidad que rebelan y porque muestra el buen conocimiento que tenían los eclesiásticos del sistema al que estaban sometidos. Para terminar su primera intervención, el primado polaco vuelve sobre lo que más le interesa: pide al papa que, cuando regrese a Roma, refuerce con un mensaje el aliento que ha dado a los jóvenes en su encuentro con ellos. La petición encaja perfectamente con la visión que tenía de cómo podían desarrollarse los acontecimientos. Hacía falta trabajar en la fortaleza de la fe de las siguientes generaciones, estar preparados para un esfuerzo largo, sostenido sobre bases sólidas, que quizá tardara mucho en llegar.

Hemos seleccionado tres intervenciones de otros obispos polacos que hicieron referencia a asuntos internacionales. Jerzy Stroba se interroga sobre la mirada del mundo sobre Polonia. Después de despreciarla o compadecerla, o de verla como indicio de una amenaza, ahora que el mundo vuelve de nuevo los ojos sobre ella ¿qué ven?, ¿qué buscan?, ¿les interesa realmente lo religioso, o miran únicamente movidos por curiosidad sociológica o política? Juan Pablo II contesta con una valoración optimista del despertar de la sensibilidad religiosa en Occidente, explica que le parece detectar una vuelta a la necesidad del espíritu y una superación de las alienaciones políticas, nacida de la constatación de su insuficiencia en términos efectivos. La retórica materialista vacía se está agotando y se avecinan cambios.

Otras dos intervenciones, de Lech Kaczmarek e Ignacy Tokarczuk, coinciden en hacer referencia a la cuestión del respeto a la dignidad y los derechos humanos y a la necesidad de recuperar un horizonte esperanzado, alejándose de la visión errónea que alimentaba el espíritu de la Ostpolitik, la alemana y la vaticana, y que facilitaba la pervivencia de la injusticia comunista y su corte de 
sufrimientos al ocultarla al mundo y, especialmente, al resto de los católicos. El comunismo, además de opresor y represor de cristianos, habría sido el ladrón y corruptor de grandes ideales como la justicia y la democracia, y la Iglesia debería ser consciente de que le compete a ella, portadora de una gran riqueza, recuperarlos para la vida social. Tokarczuk se refiere concretamente a la política del presidente norteamericano Jimmy Carter como un aliado para trabajar en ese sentido, y relata al papa la emocionada alegría de algunas personas en Moscú cuando conocieron la elección de un polaco para la silla de Pedro: ese hecho había materializado la esperanza del final de una época de dolor y tiranía que parecía hasta entonces inamovible.

La respuesta de Juan Pablo II no eludió lo más difícil del asunto. Explicó que la visión deformada de la realidad de los países socialistas era una realidad fuera de ellos, también en Roma, y también que no parecía posible hacer que se transformara hasta coincidir con lo que se veía desde Polonia. Pero insistió en que era indeseable cualquier acuerdo con autoridades comunistas que ocultara la verdad. Pablo VI, reflexionaba, seguramente también lo pensaba así, pero dependía demasiado de los informes de los nuncios, y aprobó una política que debía cambiar. A partir de ahí se inicia un interesante excurso sobre la insuficiencia de los nuncios como gestores de algunas cuestiones de gobierno y como agentes de la política eclesiástica, idea que motivó una nueva intervención del primado para recalcar lo insensato que le parecía confiar en los nuncios para una cuestión de tanta trascendencia y para la que, según él, no estaban preparados.

Al hilo de este razonamiento hay un apunte de Wyszyński que nos parece de interés porque conecta con una idea central, formulada al comienzo de la reunión: la política de «normalización» de las relaciones Iglesia-Estado en Polonia, preconizada por algunos diplomáticos vaticanos, mostraba una tendencia a sociologizar la acción y la vida de la Iglesia, cuando lo importante no eran los datos sociológicos, sino lo que el papa había dicho en su homilía en la plaza de la Victoria: Cristo. Ese enfoque, radicalmente religioso y cristocéntrico, frente a consideraciones políticas más mundanas, forma parte del núcleo de la visión de los acontecimientos que emana del acta de la conversación.

Juan Pablo II contestó a la cuestión de los nuncios matizando las afirmaciones, reconociendo los límites de su actividad, y distinguiendo ámbitos y situaciones. En conjunto, viene a decir, la fuerza de la Iglesia en un territorio se apoya más en el episcopado nacional que en la acción de un nuncio, salvo que la Iglesia esté muy en los comienzos en ese territorio.

A partir de ahí, el papa entró en unas reflexiones finales que contienen declaraciones de gran calado en la formulación de sus líneas pastorales y en la de- 
finición de su acción como pastor supremo de la Iglesia. La normalización de las relaciones de la Iglesia con el Estado, dijo, era algo secundario. Lo esencial no era una cuestión de leyes. Los ejemplos mexicano y polaco le parecían paradigmáticos. En los dos países el poder político buscaba degradar y someter a la Iglesia, en uno mediante las leyes, en otro mediante un sistema completo de control social, pero para la Iglesia esto no era determinante. Si la Iglesia era «fuerte con su propia fuerza», en el sentido de estar radicada en Cristo y guiada hacia Él, todo lo demás era secundario. Y resumía así su postura: «Mi principal objetivo es luchar por Iglesias fuertes».

\section{VERSIÓN ESPAÑOLA DE LA TRANSCRIPCIÓN DE LOS CONTENIDOS DE LA REUNIÓN DEL CONSEJO GENERAL DEL EPISCOPADO POLACO EL 5 DE JUNIO DE 1979}

\section{Protocolo del Consejo General de la Conferencia del Episcopado de Polonia}

A petición del Santo Padre Juan Pablo II, el Consejo General de la Conferencia del Episcopado de Polonia se reunió en Jasna Góra. El Santo Padre quiso esta reunión con el fin de compartir con el Consejo las primeras reflexiones y escuchar su opinión sobre ciertos temas.

\section{(...)}

El Santo Padre agradeció al primado la introducción al diálogo que quería tener con el Consejo General. Lo hace en el espíritu de colegialidad, que es la forma de estar en la Iglesia. El diálogo es una fórmula invencible. Lo que el Santo Padre experimentó en Polonia desde el principio de su visita confirmó esa tesis. Así quedó manifiesto en la Plaza de la Victoria en Varsovia.

El Santo Padre podría haber dicho: «Dejad de aplaudir», pero escuchó una voz interior: «no debes decir eso. Ellos tienen derecho a hacerlo, aunque resulte incómodo para alguien, aunque pueda dar lugar a temores». Qué hermosamente se manifestó el anhelo de Cristo por la sociedad de la capital.

El Santo Padre también expresó su alegría por la reunión con el Consejo General. -Echo de menos el estilo del trabajo del Consejo General- dijo. Siempre me alegra mucho y me atrae un intercambio libre del pensamiento. Os estaría muy agradecido -continuó- si quisierais decirle al papa qué es lo que pensáis y sentís.

(...) Estas son las palabras del Santo Padre transcritas desde la grabación. 
-Debemos darnos cuenta juntos al principio de esta conversación -continuó el papa- de que Polonia ya no está situada sólo en Polonia, sino en el mundo entero, y tampoco sólo en Europa. Yo ya me había dado cuenta de ello en el Concilio Vaticano mientras escuchaba el discurso, especialmente del primado, y traté de entender el significado de su autoridad. Ya entonces tenía una gran autoridad mundial muy clara, porque los asuntos que están sucediendo en Polonia son de importancia mundial. La conclusión, esta conversación es por tanto tan importante para mí, porque en mi ministerio hoy en día, lo que el episcopado polaco piensa, especialmente el Consejo General, es muy importante. Este es un asunto general.

Por supuesto, cuando se trata de la llamada política hacia Europa del Este ${ }^{20}$, tiene su propio significado estrecho: se centra en las actividades de Pablo VI hacia los países del bloque soviético. No se pueden revertir estas acciones, hay que continuarlas. En varias ocasiones se han expresado en la prensa occidental opiniones de este tipo: el papa continuará la política oriental, porque en este momento él es el mayor experto en política oriental; antes se acusaba al Vaticano de carecer de tales expertos. No es que no tenga expertos, lo que no tiene son personas que tengan experiencia y estén libres de complejos. Todo Occidente está cargado de complejos, de múltiples complejos. Está, en cierto sentido, desdibujado ideológicamente. Está empezando a salir un poco ahora. Creo que toda esta iniciativa del Parlamento Europeo y la unificación de Europa tiene como objetivo salir de este complejo ${ }^{21}$.

El segundo punto, más cercano, es, por supuesto, el asunto de ese viaje, que aún hoy no podemos evaluar. Deberíamos pensar ya un poco en expresarlo, en explotarlo hasta el final. El hecho de que se haya convertido en un hecho es sin duda una obra de la Divina Providencia, como dije ayer. El primado asumió en el programa de su propio ministerio pastoral que el papa vendría a Polonia y aquí está. Todo este viaje, que por necesidad estamos considerando aquí en nuestras propias dimensiones, en nuestro propio patio, tiene un significado mundial. En cierto sentido, es más, tiene más entidad que el viaje a México y la opinión, que se repitió a menudo en la prensa occidental, fue que este viaje es mucho más difícil para el papa. Así que es muy importante algún tipo de reflexión sobre

20 La expresión literal utilizada fue «política oriental», lo que en aquellos años se conocía en los medios de comunicación en España como la Ostpolitik vaticana, término prestado de la Ostpolitik del canciller alemán Willy Brandt hacia el bloque oriental, sobre todo Alemania Oriental. Acerca del uso habitual del término para describir opiniones entre eclesiásticos, puede verse Jean-Dominique DURAND, Le Cardinal Giuseppe Siri entre Occident et communisme, en Jean-Marie AUWERS, Dries VANYSACKER (eds.), Pulchritudo tam aniqua et tam nova. Études d'Histoire du christianisme en l'boneur de Mathijs Lamberigts, Turnhout, 2020, pp. 309-321.

21 Elección por sufragio universal del Parlamento Europeo. 
cómo pronunciarlo al final aquí y cómo pronunciarlo después hasta el final ${ }^{22}$. Por supuesto, tenemos que esperar los resultados de las deliberaciones del Consejo General a finales de junio, pero algunas cosas sería bueno escucharlas ahora. Ya estoy terminando mi introducción.

Personalmente, creo que este viaje de vuelta a casa debe presentarse con gran énfasis, por supuesto, no sólo ante la nación y la Iglesia, sino también ante las autoridades, incluido el Sr. Gierek y el Sr. Jabłoński, para decir: señores, este ha sido el paso valiente que han dado ustedes. Ustedes dicen, ustedes escriben, que el papa, la Santa Sede, deben trabajar por la paz, por el acercamiento entre las naciones, por la amistad entre las naciones. Si eso es cierto, significa que la Santa Sede y este papa tienen algún billete de tren o de avión a Polonia, ¿o tal vez no sólo a Polonia? En cualquier caso, han dado un paso valiente desde el punto de vista de su propia política, al menos desde su propio programa. Creo que es necesario hablarles de esta manera para protegerlos, para que su carta pueda jugarse a nuestra manera en este enorme campo de juego mundial. $\mathrm{Y}$ al mismo tiempo es necesario que jugar de esta manera no cause ningún daño, porque por supuesto todos entendemos -tal y como le sigo explicando a Casaroli ${ }^{23}$ - que todavía tenemos un gran argumento: recuerden, señores, que el papa, cuando viene aquí, arriesga más que ustedes ante el mundo entero. Porque se arriesga a darles una coartada que no se merecen. Así es como tienen que decírselo en su totalidad.

Todavía hay que escuchar todos estos discursos hasta el final. Me he estado devanando los sesos durante mucho tiempo sobre qué decir aquí. Debo admitir que preparar un texto para México me costó muy poco, ya que lo hicieron otros. Yo sólo lo miré y dije: borrad esto, añadid aquello, y también escribí alguna parte; ante todo el idioma fue un factor decisivo. Aquí tuve que escribir todo yo mismo de la A a la Z, y no dejaba de preguntarme una cosa: que esta amplia opinión occidental sopesaría lo que el papa dijo en México y lo que ha dicho en Polonia. En México hablé muy directamente sobre la injusticia que existe allí; también podría hablar aquí, pero me he detenido a mitad de camino. Fue suficiente con ponernos

22 En este contexto, el verbo polaco, dopowiedzieć, significa hablar de algo hasta el final, zanjar un asunto verbalmente.

23 El cardenal Agostino Casaroli (1914-1998) fue un diplomático y secretario de Estado de la Sede Apostólica. En los años 50 desarrolló su actividad diplomática en América Latina. Fue un estrecho colaborador de los consecutivos papas: Juan XXIII, Pablo VI, Juan Pablo I y Juan Pablo II, responsable principalmente de las relaciones con los regímenes comunistas, en las que fue partidario de un diálogo pragmático. Su postura fue criticada por los episcopados de la Iglesias sometidas a la opresión comunista por una excesiva aquiescencia. Fue autor de la idea de incluir en el derecho internacional la libertad religiosa como un inalienable derecho humano, que fue materializada en el Acta Final de CSCE de Helsinki en 1975. A pesar de ciertas diferencias de planteamiento entre ambos, poco después del primer viaje a Polonia Juan Pablo II lo nombró secretario de estado y cardenal. Véase: George WeIGEL, Fuan Pablo II: el final y el principio, Barcelona, 2011, pp. 66-71 y 106-114. 
de acuerdo en nuestros propios asuntos, los de familia, en la Plaza de la Victoria, ante Santa Ana, en la Colina del Lech en Gniezno -en nuestros propios asuntos-.

Tal vez sea suficiente para poner en marcha el Consejo General, para que pueda escuchar las voces relacionadas con los dos temas en particular: 1. Recuerden que la Iglesia polaca tiene una posición mundial, lo quiera o no. El hecho de que el papa haya sido elegido de Polonia es sólo una prueba de ello. Este problema debería estar constantemente presente en el pensamiento de la Iglesia en Polonia: ¿por qué las experiencias de la Iglesia en Polonia se han vuelto necesarias para toda la Iglesia? La Iglesia en Polonia se ha hecho y sigue haciéndose necesaria, y en dimensiones universales - al sur, al norte- en todas partes. 2. La cuestión de este viaje y de sacar de él las conclusiones correctas, lo que nos ayudaría -junto con nuestras autoridades políticas- porque nadie tiene interés en ello, de modo que se sentirían amenazados. Sé que, por el momento, no puede gobernar en Polonia nadie más -deben gobernar ellos-. La cosa es que, al menos, gobierne gente del Sr. Gierek.

\section{El primado}

Quizás su Santidad me permita añadir algo, y espero que los participantes de esta reunión añadan algo desde su punto de vista.

Creo que después de esta importantísima peregrinación del Santo Padre a Polonia, necesitaremos algún tiempo para estudiar el asunto honesta, completa y objetivamente, para recopilar relatos, voces y rumores de la prensa no sólo internacional, sino también nacional. La prensa nacional no nos dirá mucho, en realidad nada. Pero la gente que piensa, habla -y debemos hacer lo que hicimos antes de la decisión final del Santo Padre de visitarnos-. ¿Qué hemos hecho? Hablamos con todo tipo de personas. El obispo Dąbrowski le dedicó mucho tiempo, y yo también, a gente de todo tipo de puntos de vista distintos. Me he puesto en contacto con las personas más cercanas al Sr. Gierek, como el profesor Szczepański ${ }^{24}$, que es protestante y que me dijo palabras muy significativas: «Vuestra suerte en la Iglesia es que no tenéis la radio o la televisión, sino una palabra viva y un púlpito». Le expresé mi temor a que nos quedáramos cortos en este ámbito de llegar a la sociedad, y él me dijo: «Una palabra viva es un estigma». El profesor, un hombre laico. Dice claramente que la suerte de la Iglesia Católica es que usa la palabra viva del púlpito. Se trata de hacerlo bien.

Tenemos relatos permanentes sobre lo que está pasando en la sociedad de la intelligentsia polaca, lo que está pasando en el círculo del partido comunista. Allí evaluaron los pros y los contras del esperado viaje del Santo Padre. Hubo situaciones en las que sólo el propio Sr. Gierek quedó aislado en este asunto. Inicialmen-

24 Jan Szczepański, sociólogo, en 1979 fue diputado del Sejm, vicepresidente de la Academia de las Ciencias de Polonia y miembro del Consejo de Estado. 
te, casi todos aquellos que tenían algo que decir estaban en contra de la llegada. Más tarde comenzaron a inclinarse a favor de la visita. Este elemento se utilizó para luchar contra Gierek. La orientación pro-rusa proponía que el papa viniera y que viniera de inmediato, en el mes de mayo, en la fiesta de San Estanislao, con la esperanza de que finalmente se le tumbase ese plan al Sr. Gierek, que se había involucrado en el tema. Más tarde, él sucumbió a la presión y se opuso con fuerza a la llegada del papa durante la fiesta de San Estanislao a principios de mayo. El Sr. Gierek también se involucró mucho en la conversación conmigo y utilizó los materiales históricos contra San Estanislao que le habían preparado.

Hablando de eso con el Sr. Gierek el 24 de enero de 1979, le dije que este tipo de escritura y este tipo de historia es la alienación más dañina de la psique polaca, y es necesario romper con ella. Le dije: Señores, si el Santo Padre no viene, la Iglesia no perderá nada, porque la Iglesia todavía cree y cree jerárquicamente. Pero sobre ustedes recaerá la responsabilidad de ello. Si el Santo Padre viene, ustedes también pueden beneficiarse de él. Una gran parte de la opinión pública dirá: sin embargo, no son los peores, piensan un poco en polaco, porque han aceptado la llegada del Santo Padre.

Esa fue mi primera conversación con el Sr. Gierek, cuyos elementos Su Santidad conoce porque le envié todo el discurso, que no fue ni agradable ni fácil. Tuve que decir: -caballeros, o un ascetismo en el partido o su desaparición-. ¿Es una ventaja para nosotros si ustedes desaparecen? Bastante dudoso, porque en esta disposición del bloque, ¿cómo será el próximo partido? Os preferimos a vosotros que a lo desconocido. Pero si queréis aguantar, tenéis que poneros las pilas. Debéis cortar con proteger a los seguidores del partido, con vivir a expensas de Polonia, de la nación, de la alienación cultural, moral y psicológica a través de la mentira, a través del uso de imágenes y espejismos engañosos con la ayuda de la censura. Más aún, dije, el papa viene y habrá una especie de prueba para la sociedad. ¿`Y entonces qué? Ustedes, caballeros, se quedarán a un lado.

Esta fue una de las conversaciones más fundamentales y difíciles para el Sr. Gierek. La conversación fue difícil, nos dijo algunas cosas desagradables, pero reveló su preocupación por Polonia. Así que hay algún elemento de comprensión.

Todo lo que pasó entre nosotros tuvo su continuación más tarde, cuando unos días antes de la llegada de Su Santidad pedí una conversación. No estaban ansiosos por hablar. Sin embargo, dije: al igual que hubo una reunión antes del viaje del Sr. Gierek a Roma, ahora debe haber una reunión antes de la llegada del Santo Padre. ¿Para qué? Para igualar la opinión pública. Entonces se trataba de aquello por lo que luchaba el obispo Dąbrowski -sobre este tipo de igualdad de acceso a los medios de comunicación, información, mensajes, alimentos, etc.- No dijimos casi nada sobre la seguridad del Santo Padre, ya que esperábamos una atmósfera religiosa, que se rige por sus propias leyes psicológicas. Sin embargo, sólo hablaron de eso. Sólo más tarde empezaron a hablar de las dificultades de aprovisionamiento y de la comunicación. 
¿Cómo podemos evaluar la actitud de la sociedad a este respecto?

Toda la sociedad estaba absolutamente cohesionada y uniforme, aunque había quienes consideraban que era una prueba de fuerza entre la Iglesia y el partido: vendrá o no vendrá; había personas que creían que no se trataba sólo de una prueba de fuerza, sino de algún tipo de ayuda para la Iglesia. La presencia del papa en un Estado del bloque es una especie de rotura en el telón de acero del bloque, es el despertar de Lituania y Letonia, y Estonia, y Bielorrusia, y Ucrania, y de aquellos católicos que viven en el mundo oriental, y es una especie de renacimiento de la esperanza de estas gentes. Si no se hubiese producido la visita, la Iglesia se lo explicaría, se fortalecería y continuaría trabajando, pero ¿qué pasaría con las esperanzas, sobre todo con las de Lituania y Letonia? Esas personas necesitan apoyo. La presencia del Santo Padre aquí en Polonia es un aumento de esperanza, una especie de movilización espiritual, un renacimiento de la fe de esas personas en que sí se puede hacer algo si se adopta una actitud contundente.

En la última conversación, es decir, el 29 de mayo de 1979, el Sr. Gierek dijo:

Yo no ganaré nada con esta visita - en el sentido de que se intensificaría la lucha contra él-. El adversario ya ha movilizado a sus bases para llevar a cabo acciones después de la partida del Santo Padre, porque será necesario terminar con Gierek y sus seguidores, ya que al permitir que el Santo Padre venga se ha activado la clericalización de Polonia.

Los opositores, allí donde pudieron hacer alguna faena, no dudaron en hacerla. Por ejemplo, en el último momento, dos días antes de la llegada a Gniezno, anunciaron que todos los trenes habían sido cancelados. El obispo Michalski ${ }^{25}$ es un gran hombre en todas las dimensiones. Incluso él, que supo encontrar un lenguaje común con el presidente del voivoidato de Poznań, que le había hecho de todo -la ciudad abandonada fue renovada-, se quebró un poco, pero no cedió; el obispo Jan le montó broncas a quien fue necesario y los trenes comenzaron a funcionar en el último momento, especialmente los de enlace: InowrocławGniezno, Poznań-Września, y los jóvenes con los que el Santo Padre mantuvo su diálogo pudieron regresar porque los trenes estaban allí esperándolos. Esto demuestra que, dondequiera que pudieron fastidiar algo, no dudaron en hacerlo. (...)

Cuando finalmente aprobaron que el Santo Padre podía venir a Polonia, al mismo tiempo postularon: pero sin triunfalismo, pero sin vencedores ni vencidos -que no haya tal terminología-. Nosotros no contestamos nada. Los hechos dieron la respuesta. Y por eso, donde pudieron, daban noticias que llevaban al error. Vendrá, no vendrá; le dejarán entrar, no le dejarán: de eso hubo un montón. Cuando lo recopilemos, podremos decir algo a la sociedad católica.

25 Jan Michalski, obispo auxiliar de la archidiócesis de Gniezno. 
Si me permite una petición, Santo Padre, creo que cuando Su Santidad regrese a Roma, será agradable para nosotros recibir una breve carta en la que el mismo Santo Padre exprese su satisfacción por un contacto tan vivo. Ese encuentro con los jóvenes en Gniezno el domingo por la tarde fue fantástico, aunque el Santo Padre estaba muy cansado y su gente estaba preocupada por cómo terminaría. De esa manera, el Santo Padre mostró la actitud que tiene hacia la sociedad, los obispos, el clero, las órdenes religiosas -incluido el primado-; todo esto es una gran oportunidad para crear esta verdadera impresión de cómo es esta comunidad eclesial en la Iglesia de Dios. Por el momento estamos animados, unidos, cimentados y fortalecidos en el espíritu. El principio de Cristo ha sido implementado: Confirma fratres tuos. ¡Que Dios le bendiga por todo!

\section{Arzobispo Stroba}

\section{(...)}

En relación con lo que el Santo Padre ha dicho, debemos sobre todo preguntar de acuerdo con las etapas de la Iglesia en Polonia. En primer lugar, hubo una etapa de desprecio, que surgió de un sentido de superioridad; luego hubo otra percepción de cualidades positivas, pero también un intento de explicar que eso era un resultado del atraso; y hoy hay un sentido de amenaza, que abre cada vez más los ojos a esta Iglesia en Polonia. Y me parece que la perspectiva desde la que el Santo Padre la mira, sería importante si nos dijera incluso cómo debemos sobre todo revelarla, cómo debemos hacerla conocer. Sin duda, este es el momento de la verdad sobre el que Su Santidad ha hablado hoy; este es, sin duda, el momento de la primacía de los valores morales, del cimiento; este es, sin duda, el problema de los derechos humanos, pero es aún más el problema de los valores religiosos en los que ya no creen, o al menos en los que su fe está sacudida. Este es el problema de los valores de la fe y la oración, que siempre menciona su Eminencia, y probablemente del sacrificio. Desde esta perspectiva desde la que Su Santidad nos mira, ¿hay algo más que ver?, ¿el mundo que se dirige a Polonia no siente la necesidad de su testimonio, sobre todo, y es eso lo que espera de nosotros? Esta es la primera pregunta.

\section{(...)}

\section{El Santo Padre}

En cuanto a las perspectivas del mundo, en este momento se habla mucho del despertar de la necesidad del espíritu, de la necesidad del novum sacrum. En Italia escriben sobre ello, incluso se preocupan por ello. Pasa por el mundo, pasa por Italia. Se preocupan por ello principalmente cuando se trata de programas políticos, lo que se ha confirmado un poco en estos últimos días, porque los comunistas han perdido mucho. Este despertar del sacrum pasa por el mundo, pasa por la juventud, en todas las direcciones. Se puede sentir. 
Creo que también hay otro proceso que aún no es visible, el proceso de liberarse de las alienaciones políticas. Se puede ver que hay una especie de brecha entre el trabajo de propaganda, con una sólida base económica, por parte de los partidos políticos, y la vida de la sociedad. La política es un arte para sí misma. Así que se avecinan algunos cambios. Se puede sentir.

(...)

\section{Obispo Kaczmarek}

Hoy he hablado con un francés que me hizo esta pregunta: si la visita del papa a Polonia influirá en unir al conjunto de la nación. Y yo le respondí que, ciertamente, tendrá que influir en unirlo religiosamente. ¿Pero tendrá una influencia política unificadora?

Me gustaría enfatizar el hecho de que los discursos de Su Santidad han sido poderosos y equilibrados. No se ha dicho ni una sola palabra que fuera provocativa y que debiera retirarse. Sin embargo, se ha insistido con mucho cuidado y énfasis en la cuestión más importante de nuestros tiempos, que es la clave de todas las reflexiones de nuestra época, a saber, en la cuestión de los derechos humanos y la dignidad humana.

\section{El obispo Tokarczuk}

Un tema extremadamente importante es la Ostpolitik -unirse a la causa para despertar la solidaridad con los que sufren en toda la Iglesia-. Después de todo, si algo le pasa a uno de los comunistas, todos los comunistas se ponen a gritar.

La segunda cosa: es necesario despertar la confianza de la Iglesia en su propia fuerza, en su propia verdad. Hemos sufrido una terrible caída, una pérdida, cometimos el error de aceptar las palabras de aquellas grandes declaraciones y así el comunismo robó realmente todas las obras de la mente humana en el curso de la historia, como la justicia y la democracia. Por eso ahora tenemos que despertar algo de confianza.

En cuanto a los derechos humanos, como observo después de esta ola de Carter, la Santa Sede ha aceptado un problema moral, un retorno de la moralidad a la política, que no puede ser resuelto sin ética, sin moralidad. Aquí viene un papel importante para la Iglesia. Esto puede que no guste a unos u otros, pero básicamente todas las personas de buena voluntad, sobre todo las que sufren, pueden sentirlo, y este es en realidad, entre otros, el significado de la Iglesia: ser la conciencia del mundo.

A este respecto, me gustaría decir qué ecos hay en el Este. Después de la elección de un polaco como papa, una parte de los moscovitas lloró de alegría. Tal es el entusiasmo, la esperanza y la expectativa. Lo mismo en Lituania. Cuánto agradeció la gente que el día de su inauguración el papa hablara en sus idiomas. Eran naciones que se conocen. El espíritu de los lituanos se elevó en un 100\%, 
al igual que el de los ucranianos. Esto nos facilita enormemente las relaciones polaco-ucranianas. De todos modos, todos están mirando y agradeciendo a Dios con gran gratitud y esperanza.

(...)

\section{El Santo Padre}

(...)

El papa mismo se pone a ello, qué podemos aconsejarle. Independientemente de este hecho, que tiene sus consecuencias directas, hay un problema de cierta estructura, cierta actividad, debido simplemente al principio en el que hemos entrado, de que la Iglesia en Polonia, que tiene sus propios asuntos y trata con el gobierno, con las autoridades polacas, aquí en el terreno de su propia nación, de su sociedad, se siente al mismo tiempo parte de la Iglesia universal y, por su parte, se esfuerza por este acuerdo de carácter supremo e internacional -de hecho, un acuerdo entre la Santa Sede, que representa la dimensión universal de la Iglesiay el gobierno. No puede ser un acuerdo cualquiera. Si ha de ser cualquiera, si ha de ser ficticio, si ha de tapar la verdad, es mejor que no lo haya, para no crear ilusiones. Todos estamos de acuerdo en eso, tanto aquí como allá. Creo que Pablo VI también lo pensaba, aunque era un hombre salido de la división de la Curia Romana. No era un diplomático, sin embargo, creció y tuvo -como bien sabemos- su visión de los contactos con las Iglesias locales. Esa visión se basaba en la institución de los nuncios. La estudiamos nosotros mismos en nuestros Consejos Generales. Por supuesto, observo el trabajo de los nuncios en diferentes países porque los recibo constantemente.

No hay duda de que, en la dimensión general, especialmente cuando se trata de las Iglesias más débiles, más jóvenes, de un potencial aún pequeño, de entornos humanos pequeños, la labor del nuncio es básicamente inestimable. Ellos ayudan en gran medida a estas Iglesias a formarse, a establecerse. Las nunciaturas en países grandes y problemáticos son muy difíciles, como veo por lo que me llega, por lo que estoy estudiando. La cosa es diversa. Hay que aplicar más criterios, ya que no se puede juzgar según un solo criterio.

(...)

\section{El primado}

Considero que es mi deber de conciencia responder en la escala en la que hablamos en el Consejo General, en el que el Santo Padre tomó parte activa como metropolitano de Cracovia.

Se trata de la cuestión de la nunciatura y sus competencias. Estas competencias van muy lejos. Una vez tuve la oportunidad de leer el acta de una reunión secreta de los nuncios, que sugería que la jerarquía inferior apenas tiene significado y no tiene ninguna relación con la Santa Sede. Me dijeron que no dijera nada sobre el 
hecho de que conozco tales actas, y respondí que era imposible, ya que se trataba de la Iglesia. Se lo conté al papa Pablo VI. Se quedó asombrado. Mi conversación con Pablo VI fue muy triste, muy dura. Era la primera vez que veía al papa tan a la defensiva. Dijo: están ahí para ayudar. Y yo le dije: ¿cómo pueden ayudar si no conocen la situación? Y no pueden conocer la situación sin conocer los antecedentes históricos y el desarrollo de este país. El Santo Padre los defendió mucho. No critiqué a la institución, pero dije: esos nuncios deben ser formados de otra manera. En primer lugar, el programa de estudios de la escuela en la que se preparan es definitivamente demasiado pobre, demasiado modesto. Se les debería exigir que conozcan la historia de un país determinado, es decir, la historia de Polonia. Por eso busqué el texto francés del libro La Santa Sede y Rusia y se lo di a Poggi ${ }^{26}$ : Léelo, hermano, es sólo un pequeño episodio. Pero él dijo: No tengo tiempo para eso. Porque si un hombre está hoy en Polonia, mañana en Hungría y pasado mañana en otro lugar, es absolutamente incapaz de entrar de verdad en la mentalidad religiosa, moral, social, política de un país dado. Sólo un hombre muy inteligente y de gran valor podría hacer eso.

Cuando Poggi vino, queríamos que complementara aquí su formación. Por eso creamos las condiciones para que viajara a diferentes diócesis. Pero él de alguna manera no era docibilis en este sentido. Sin embargo, era sensible a los chivatos y por eso surgieron varios asuntos desagradables. Entonces le dije al Santo Padre que no era posible confiar en la información de un hombre que vendría al país por un día, dos o una semana e ignorar nuestra información. Que el Santo Padre preguntase a los obispos, que preguntase al Consejo General, que me preguntase a mí.

¿De dónde vienen estas cosas? De la meticulosidad de Poggi y su tendencia a recoger cotilleos. Por eso me parece, y el Santo Padre hará lo que crea, que en este momento la posición de Poggi en Polonia está acabada. Es un perdedor. ¿Por qué? Porque, aparte del episcopado, aparte de las informaciones más diversas, quería recoger noticias. Ese no es un trabajo del nuncio especial. Es el deber de los obispos locales. Que hable con el gobierno, que se ocupe de la normalización, no de la administración local. Es asunto nuestro. Cuando se presente el caso, lo presentaremos al Santo Padre. Y mientras tanto, ha ocurrido otra cosa.

Cuando se trata de la llamada normalización, el gobierno no quiere la normalización en el sentido legal. Eso es un hecho. Les gustaría que la normalización fuera algún tipo de protocolo, algún tipo de comunicado, pero nunca el reconocimiento de la Iglesia como un sujeto de derecho público. Hemos hablado mucho de eso. Ellos no quieren eso. Ya ni hablo del concordato. De todos modos, incluso si se creara un documento legal de este tipo, podría ser un obstáculo, porque después lo aplicarían ad litteram -y lo usarían contra la Iglesia-.

26 Arzobispo Luigi Poggi, nuncio apostólico en Polonia. 
Y lo más importante - cosa curiosa, cuando se trata de la función del nunciomuchos episcopados dicen: defendeos de los nuncios.

No significa, Santidad, que queramos socavar la importancia de una institución que tiene sus méritos. El papel de los nuncios a escala mundial, sí. Digamos que en una situación como la de los Países Bajos, Alemania, Bélgica -ellos, sobre todo cuando se trata de influir en los nombramientos de los obispos para protegerlos de los nombramientos, de las actuaciones que saldrían del ambiente nacional- pueden tener algún significado. Sin embargo, me parece que la cuestión de la presentación de los candidatos a la Santa Sede de los obispos debe dejarse firmemente en manos del Consejo General (a la Conferencia Episcopal sólo modo consultivo). Se trata de asuntos delicados y a veces se necesita una buena comprensión de la situación y alguna experiencia.

(...)

\section{El primado}

El significado propio de la normalización no es sólo en el sentido jurídico, sino también en el teológico. Porque hoy en día hay una tendencia a sociologizar la Iglesia en todos los campos, tanto el teológico como el pastoral, es decir, lo que el Santo Padre dijo en sus discursos y en la Plaza de la Victoria: Cristo. Cristo como la parte plena salvadora de la familia humana; toda la Plaza reaccionó vívidamente a esto. Porque el Espíritu Santo está en la Iglesia. Así que, Cristo. En estas conversaciones no sólo se trata de encontrar una fórmula legal, sino que también se trata de Cristo, de su enseñanza, del Evangelio, de los principios teológicos y sociales y morales de Cristo que la Iglesia da a aquellas sociedades quebrantadas, porque unas se desahogan en el sociologismo, otras en el economicismo, y otras, en general, en la falta de un programa.

\section{El Santo Padre}

En cierto modo, estas dos primeras visitas confirman una tesis: una Iglesia fuerte en el Estado más contrario: México y Polonia -estas son las dos posiciones: la Iglesia fuerte con su propia fuerza-.

Si nos atenemos a esta visión -una Iglesia poderosa- ciertamente la Iglesia es en gran parte fuerte con su episcopado. Mi principal objetivo es luchar por Iglesias fuertes. Y la cuestión de cómo estas diversas instituciones de la Curia Romana -incluyendo las instituciones del episcopado- van a jugar en todo esto es un tema derivado. Puedo ver que a veces, y sobre todo en la situación del Tercer Mundo, en la situación de las Iglesias minoritarias, los nuncios cumplen su función ya que ellos no se apañan todavía. Este asunto puede considerarse como completamente explicado. Sólo quería añadir, constatar, que lo básico es la fuerza de la Iglesia a través de un fuerte episcopado nacional, fuerte por su propia fuerza. Y todo el tema de la normalización de las relaciones con el Estado es secundario. 
La visita a México es un ejemplo de esto. Una Iglesia fuerte se ha manifestado en un país donde la Iglesia está degradada por la ley, por la Constitución, como en ningún otro lugar del mundo. La visita a Polonia es una segunda confirmación, excepto que en nuestro caso la Iglesia no está tan degradada por la ley, sino que está degradada por el sistema. Esta es la conclusión principal.

(...)

\section{CONCLUSIONES}

El documento que hemos presentado tiene una riqueza singular que le confiere un especial interés histórico. Recoge una conversación de pastores de la Iglesia, incluido el que los encabeza en todo el mundo, que trata sobre asuntos eclesiásticos, pero también de sus efectos políticos, bien conocidos por los interlocutores. La cuestión de la relación entre religión y política es siempre compleja y difícil de describir, y este documento la ilumina intensamente en la época en que se produjo, un tiempo de particular densidad histórica y clave en el devenir del final del siglo $\mathrm{XX}$.

Una de las características de esa centuria, con evidentes raíces en las anteriores, fueron las llamadas «religiones políticas»: concepciones del gobierno de lo público que se asimilaron a las formas de las organizaciones religiosas e intentaron ser vividas con la misma hondura que los cultos religiosos y con el mismo grado de asentimiento personal que las creencias. Su pretensión era acaparar todo el poder, que nada en la vida social quedara fuera de su control o al menos de su influjo, que nadie pudiera competir con ellas ni limitarlas. Una de las formas más acabadas de esas «religiones políticas» fue, por eso, el totalitarismo, fenómeno característico del siglo XX y, especialmente, el comunismo, quizá el tipo de totalitarismo más acabado y de hecho el más duradero ${ }^{27}$. Los obispos que hablaban lo eran de un país que había conocido el dominio nazi-alemán durante la Segunda Guerra Mundial y estaba bajo control comunista desde que esta había terminado. Estaban, por tanto, entre quienes mejor conocían qué significaba vivir y tratar de gobernar la Iglesia bajo gobierno totalitario.

A los especialistas en historia general nos suele interesar más el punto de vista político que el religioso; es un prejuicio del que pocos escapan. Entre muchos expertos está difundida incluso la idea de que lo religioso no es otra cosa que una for-

27 Juan Francisco Fuentes, Totalitarianisms: The Closed Society and its Friends. A History of Crossed Languages, Santander, 2019, pp. 43-57. 
ma de ejercicio del poder disfrazada de algo tan pintoresco, y para algunos siniestro, como la religión. Incluso los creyentes se enfrentan a dificultades para abordar la historia de la relación entre política y religión. La fuente que presentamos resulta en este sentido muy interesante porque representa el reverso del planteamiento común: son hombres de Iglesia que hablan de religión, que es lo que más les interesa y les preocupa, pero conscientes de sus inevitables efectos en la sociedad y, por ende, en la política. El resultado es un diálogo de alto interés religioso y también político.

La conversación del papa y los obispos polacos es un retrato crudo y sencillo de lo insoportable que resultaba la opresión comunista y de cómo, sin embargo, ellos mismos entendían que no se la podían sacudir inmediatamente. Eran bien conscientes de la fuerza que los aplastaba, pero también de cuáles eran las debilidades que la hacían quebradiza; sabían que podía ser derrotada, que no podría durar para siempre, que acabaría cayendo. Pero también sabían que intentar precipitar esa liberación podía acarrear males mayores, por eso medían en términos de fino realismo político sus acciones.

Nos parece que otro elemento muy valioso de este documento es la clarividencia de análisis que se refleja en él. Los participantes en la reunión eran conscientes de que ese viaje papal era «una brecha en el telón de Acero», comprendían que, al no tener más remedio que permitirlo, las autoridades comunistas se debían enfrentar una versión de la realidad que siempre negaban: la profunda injusticia del sistema que regentaban. Los interlocutores entendían que esto precipitaría cambios no solo en Polonia, sino en todo el centro y el este de Europa, y seguramente también en la propia URSS. Pocos analistas políticos, en realidad casi ninguno, acertaba a ver así las cosas en 1979. ¿De dónde procedía esa claridad de visión y de anticipación del futuro? La respuesta parece obvia: del conocimiento y el reconocimiento de la realidad o, si se prefiere, de la verdad. Como se ha insistido en muy diversos momentos, el gran problema del sistema comunista, y eso vale para cualquier gobierno opresivo, es que se asienta sobre una mentira ${ }^{28}$. El acta de esta reunión lo hace patente.

28 En el capítulo V de la serie Chernóbil (HBO, 2019), titulado en ruso «Vichnaya Pamyat» [La memoria eterna], el científico Valeri Legásov afirma: «I've already trod on dangerous ground. We're on dangerous ground right now. Because of our secrets and our lies. They are practically what defines us. When the truth offends, we lie and lie until we cannot even remember it's there. But it is still there. Every lie we tell incurs a debt to the truth. Sooner or later, the debt is paid». Es el centro del argumento de ese capítulo y de la serie. Esto coincide con un juicio de Juan Pablo II en el que manifiesta que la cultura y la política comunistas estaban edificadas sobre la mentira. Véase: George WEIGEL, Biografía de 7uan Pablo II... [ver n. 4], pp. 397-399 y 440-441, en donde se advierte que su juicio coincide con el de A. Solzhenitsyn. Véase también Stephen KocH, El fin de la inocencia. Willi Münzemberg y la seducción de los intelectuales, Barcelona, 1997, passim. 
Otra aportación de gran interés en esa transcripción es facilitar evidencias sobre qué es y cómo se ejercita el gobierno de la Iglesia, la polaca y la universal. Asistimos a un debate franco, totalmente abierto, entre autoridades diocesanas de un país y la cabeza de la Iglesia Católica, pero al mismo tiempo entre compatriotas que se conocen y se entienden, sin ningún tipo de filtro. Hablan de lo que les preocupa, que resulta ser la difusión del mensaje cristiano y la atención pastoral de los fieles católicos. Aparece de forma diáfana que la política es un corolario de su intención primordial. Incluso los que podríamos llamar asuntos de política eclesiástica, como la función de los nuncios y el debate sobre su papel, o las decisiones que debían tomarse en relación con los Estados, eran asuntos marginales. El centro de la conversación era lo que Wyszyński evocaba con emoción, rechazando planteamientos sociologistas: «El significado propio de la normalización no es sólo en el sentido jurídico, sino también en el teológico. Porque hoy en día hay una tendencia a sociologizar la Iglesia en todos los campos, tanto en el teológico como en el pastoral, es decir, lo que el Santo Padre dijo en sus discursos y en la Plaza de la Victoria: Cristo. Cristo como la parte plena salvadora de la familia humana; qué vívidamente reaccionó a esto toda la Plaza. Porque el Espíritu Santo está en la Iglesia. Así que, Cristo». La apreciación del primado de Polonia fue ratificada por la afirmación de Juan Pablo II de que la eficacia de la acción de la Iglesia no dependía de las circunstancias políticas en que se encontrara en cada país, sino de que fuera «una Iglesia fuerte», en el sentido de consciente de su función religiosa, unida y activa. En definitiva, Jesucristo fue el centro de la conversación. Su misteriosa presencia en la historia se concretó así en aquel diálogo de algunos sucesores de los apóstoles. Siempre será difícil describir realidades como esta, que, siendo temporales, están también fuera del tiempo. Pero no podemos decir que carezcamos de fuentes para conocerlas.

\section{REFERENCIAS BIBLIOGRÁFICAS}

ANDRÉANI, Jacques, Le piège: Helsinki et la chute du communisme, Paris, 2005.

ANDrÉs-Gallego, José, PAzos, Antón, La Iglesia en la España contemporánea (19361998), Madrid, 1999.

BENEDICTO XVI, Discurso a los cardenales, arzobispos, obispos, y prelados superiores de la curia romana, 22/12/2005, http://www.vatican.va/content/benedictxvi/es/speeches/2005/december/documents/hf_ben_xvi_spe_20051222_roman-curia.html [consultado: 22/12/2020].

BiaŁKOWSKI, Michał, Udziat Karola Wojtyly w pracach Konferencji Episkopatu Polski i jej komisji specjalistycznych (1958-1978), en Studia Salvatoriana Polonica, 12 (2018), pp. 275-321. 
BRANDT, Willy, Memorias, Madrid, 1990.

BURLEIGH, Michael, Sangre y rabia. Una historia cultural del terrorismo, Madrid, 2008.

CHAmproux, Nathalie, L'instauration du Système monétaire européen, en Entre convictions et obligations: Les gouvernements Thatcher et Major face au Système monétaire européen 1979-1997, Paris, 2009, http://books.openedition.org/psn/7815 [consultado: 22/12/2020].

Chernóbil, HBO, 2019.

DECAUX, Emmanuel, La Conférence sur la sécurité et la coopération en Europe (CSCE), Paris, 1992.

DUlSKA, Anna K., DUlski, Ryszard, Halo, halo! Niepodlegta w eterze. Radio i radiofonia w Polsce, 1918-1989, Kraków, 2021.

Durand, Jean-Dominique, Le Cardinal Giuseppe Siri entre Occident et communisme, en Jean-Marie AUWERS, Dries VANYSACKer (eds.), Pulcbritudo tam aniqua et tam nova. Études d'Histoire du christianisme en l'honeur de Mathijs Lamberigts, Turnhout, 2020, pp. 309-321.

Dyduch, Jan, Ksztatt prawny Konferencji Episkopatu Polski, en Prawo Kanoniczne, 55/2 (2012), pp. 3-15.

First Inaugural Address of Richard Mulhouse Nixon, https://avalon.law.yale.edu/20th_ century/nixon1.asp [consultado: 01/2020].

FONVIEILLE-ALQUIER, François, El Eurocomunismo, Barcelona, 1979.

FuENTES, Juan Francisco, Totalitarianisms: The Closed Society and its Friends. A History of Crossed Languages, Santander, 2019.

FURET, François, El pasado de una ilusión. Ensayo sobre la idea comunista en el siglo XX, México, 1995.

GHEBALI, Victor-Yves, La diplomatie de la détente, la CSCE, d'Helsinki á Vienne (19731989), Bruxelles, 1989.

GRAJEWSKI, Andrzej (ed.), Sprawy, które tocza się w Polsce, maja znaczenie światowe. Niepublikowane przemówienie Fana Pawta II do Rady Gtównej Episkopatu Polski, Jasna Góra, 5 czerwca 1979 r., introducción de Jan Kopiec, epílogo de Paweł Skibiński, Warszawa, 2019.

Hakkarainen, Petri, A state of peace in Europe. West Germany and the CSCE, 1966-1975, New York, 2011.

JARZĄBEK, Wanda, Polska w polityce międzynarodowej $i$ «Zimnej wojnie», 1945-1989, en Krzysztof PersaK, Paweł MACHCEWICZ, Polski wiek XX, t. IV, Warszawa, 2010, pp. 315-320.

KocH, Stephen, El fin de la inocencia. Willi Münzemberg y la seducción de los intelectuales, Barcelona, 1997.

ŁATKA, Rafał, Rada Gtówna Episkopatu Polski a pierwsza pielgrzymka Fana Pawła II do Ojczyzny w 1979 r., en Dzieje Najnowsze, 1 (2018), pp. 229-262.

ŁATKA, Rafał, Rada Gtówna Episkopatu Polski a stan wojenny, en Glaukopis 34 (2017), pp. 159-186. 
MiKRUT, Jan (ed.), La Chiesa cattolica e il comunismo: in Europa centro-orientale e in Unione Sovietica, Verona, 2016.

Mikrut, Jan (ed.), La Chiesa cattolica in Unione Sovietica: dalla Rivoluzione del 1917 alla Perestrojka, Verona, 2017.

NoCE, Augusto del, Italia y el eurocomunismo: una estrategia para occidente, Madrid, 1977.

PÉreZ López, Pablo, El mundo en que vio la luz el Concilio, en Antonio ArANDA, Miguel LLUCH, Jorge HERRERA (eds.), En torno al Vaticano II: claves históricas, doctrinales y pastorales, Pamplona, 2014, pp. 47-68.

PÉREZ LópeZ, Pablo, El pontificado de Juan Pablo II y su tiempo, en Scripta Theologica, 51 (2019), pp. 129-157. DOI 10.15581/006.51.1.129-157.

RoszKowsKi, Wojciech, Historia Polski 1914-2015, Warszawa, 2017.

SHEvCHENKO, Arkadi N., Ruptura con Moscú, Barcelona, 1985.

SouTOU, Georges-Henri, La Guerre de Cinquante ans. Les relations Est-Ouest 1943-1990, Paris 2001.

STĘPIEŃ, Marek, Status prawny i organizacja Konferencji Episkopatu Polski, en Artur MiZIŃSKI (dir.), 100-lecie Konferencji Episkopatu Polski. Księga Fubileuszowa, Kielce, 2019, pp. 52-91.

WeIGEL, George, Biografía de fuan Pablo II. Testigo de esperanza, Barcelona, 1999.

WEIGEL, George, Juan Pablo II: el final y el principio, Barcelona, 2011.

WILK, Stanisław, Poczatki Konferencji Episkopatu Polski, en Artur MIZIŃSKI (dir.), 100-lecie Konferencji Episkopatu Polski. Księga Jubileuszowa, Kielce, 2019, pp. 15-50.

WINKLER, Heinrich August, Der lange Weg nach Westen II. Deutsche Geschichte vom «Dritten Reich» bis zur Wiedervereinigung, München, 2000.

ZorgBIBE, Charles, Histoire de la construction européenne, Paris, 1993.

ZuBOK, Vladislav M., Un imperio fallido. La Unión Soviética durante la Guerra Fría, Barcelona, 2008. 



\section{CONVERSACIÓN}


